Research Article

\title{
Investigation of Corrosion Rate of Mild Steel in Fruit Juice Environment Using Factorial Experimental Design
}

\author{
Abdulhammed K. Hamzat $\mathbb{D},{ }^{1}$ Ibrahim A. Adediran, ${ }^{2}$ Luai M. Alhems $\mathbb{D},^{3}$ \\ and Muhammad $\operatorname{Riaz}^{4}$ \\ ${ }^{1}$ Department of Mechanical Engineering, King Fahd University of Petroleum and Minerals, Dhahran 31261, Saudi Arabia \\ ${ }^{2}$ Department of Mechanical Engineering, Ankara Yildirim Beyazit University, Ankara, Turkey \\ ${ }^{3}$ CER/Research Institute, King Fahd University of Petroleum and Minerals, Dhahran 31261, Saudi Arabia \\ ${ }^{4}$ Department of Mathematics and Statistics, King Fahd University of Petroleum and Minerals, Dhahran 31261, Saudi Arabia
}

Correspondence should be addressed to Abdulhammed K. Hamzat; oyelamihammed@gmail.com

Received 12 September 2019; Revised 12 December 2019; Accepted 28 December 2019; Published 27 February 2020

Academic Editor: Michael J. Schütze

Copyright (c) 2020 Abdulhammed K. Hamzat et al. This is an open access article distributed under the Creative Commons Attribution License, which permits unrestricted use, distribution, and reproduction in any medium, provided the original work is properly cited.

\begin{abstract}
Although little attention is paid to corrosion study in food processing and production industry, it is highly important to take a critical look at what transpires at the production stages and how these can affect human health due to contamination of the final product. This research employs the design of experiment module of a Minitab software to analyze the corrosion effect of mild steel in fruit juice environment. Coupon method was adopted to calculate the rate of corrosion in orange, pineapple, and cashew fluid for a duration of 25 days with measurement taken at 5-day intervals. The highest corrosion rate of $0.71 \mathrm{mmpy}$ was observed in cashew fluid followed by pineapple fluid, and the least rate of $0.08 \mathrm{mmpy}$ was observed in orange fluid. The generalized model equation was obtained to predict corrosion rate of mild steel in a similar environment. In general, design of experiment offers a better way to analyze corrosion experiment result, and this innovative idea is shown in this work.
\end{abstract}

\section{Introduction}

Serious attention is being paid to corrosion study in oil and gas industries because of its economic, safety, and conservation concerns. However, few research studies are available in the literature on corrosion in food processing industries. Fruit juice and beverages are widely consumed by the world population, but people seem to ignore the complex processing stages involved before the final product. This process involves crushing and squeezing of raw fruit for juice extraction, optional filtration, batch preparation, pasteurization, filling, and bottling [1]. Metal or alloys are always in contact with the extracted juice during these processes. This leads to the corrosion of food processing equipment because of the acidic content of the fruit. Orange, pineapple, and apple contain varying forms of acids such as citric, malic, and oxalic acids [2]. Reaction of these acids with metals during production results in corrosion of production equipment and might contaminate the processed juice which raises a serious health concern.

Corrosion is the degradation, deterioration, or destruction of metals and alloys as a result of chemical or electrochemical reaction with environment. It is also a natural way of reversing the state of materials back to its low-energy status. The impact of corrosion in food processing industries cannot be overemphasized, given the impact on production scheduling, contamination of the final product, and safety concern. This devastating impact of corrosion compels advanced countries like the United State (USA) to spend $\$ 276$ billion annually (3.1\% of the GDP) on direct corrosion cost. Of $\$ 17.6$ billion spent in the production and manufacturing sector, \$2.1 billion (12\%) was spent on food processing [3]. This further emphasizes the importance of corrosion study in food processing industries.

Mild steel is the most popularly used and cheapest form of steel, and it is referred to as mild because of its relatively 
low carbon content. Mild steel is known for its malleability, weldability, and amenability to heat treatment to vary its mechanical properties [4]. It finds application in food processing industries and everyday object we use. Kitchen utensil such as pans, pots, and spoons are sometimes made of mild steel.

Fruit juices are usually included in daily diet structure because of their nutritional values. They are widely consumed in different ways such as nutritional supplement, condiment, digestive, and health drinks. They can either be consumed as raw or processed drinks containing different additives. Owing to various additives and different processes involved in processed juice, food processing industries are prone to serious corrosion concern.

Sharma et al. [5] studied fruit juice and chloride ion effects on the corrosion behavior of orthodontic archwire. AISI 316L stainless steel of 0.018 inches $(0.0472 \mathrm{~cm})$ was used for the experiment. The fluid samples were prepared at a control amount. The samples were inserted for approximately 24 hours in artificial saliva (AS) having different fruit juices and another sample in a separate fluid juice with $1 \% \mathrm{NaCl}$ in AS. The result shows an appreciable increase in corrosion rate in AS in the presence or absence of salt. Pitting corrosion was observed upon addition of $1 \%$ of $\mathrm{NaCl}$ to the AS. Surface analysis was done using scanning electron micrograph to show blister formation on the steel surface.

Dey and Agrawal [6] performed experimental research on the corrosion effect of a tin plate container for food packaging in fruit juice environment. Coupon techniques were adopted to calculate the rate of corrosion, and scanning electron microscopy was used to study the morphological structure of the corrosion product. Test coupon of a known weight was immersed in different fruit juices containing preservatives, natural fruit juice, and water with a total exposure time of 20 days. Specimen was reweighed for possible weight loss at six-day intervals. The result showed a significant deterioration of the tin plate sheet. Corrosion is more pronounced in packed fruit juice with preservative followed by natural fruit juice and water, respectively.

Omotoso et al. [7] performed experiments on 1014 mild and 304 stainless steel in acidic media to determine the corrosion performance of the two metals. 180 metal samples were immersed in sulphuric acid $\left(\mathrm{H}_{2} \mathrm{SO}_{4}\right)$, hydrochloric acid $(\mathrm{HCl})$, and nitric acid $\left(\mathrm{HNO}_{3}\right)$ at different concentrations. The sample was exposed for 15 days and reweighed at 3-day interval for corrosion rate calculations. Energy-dispersive $\mathrm{X}$-ray (EDX) and scanning electron microscopy were used to determine the morphology of the sample. The morphological result showed pitting corrosion damage and crack development on sample surfaces. Corrosion rate increases with increasing molarities of the reagent, and that of mild steel is higher compared to stainless steel sample.

Ada et al. [8] used weight loss and electrochemical techniques to study the corrosion resistance of AISI 304L, AISI 316L, St 37.2, and nickel-coated St 37.2 steel in different fruit juice media of the Ankara Sugar Factory. The metal samples were immersed in raw juice, thin juice, and juice taken from the evaporator. Corrosion rates from different techniques was measured and compared. St 37.2 steel has the fastest cor- rosion rate, whereas stainless steel AISI $316 \mathrm{~L}$ has the slowest corrosion rate. AISI $316 \mathrm{~L}$ offers high corrosion resistance compared to AISI 304L in different juices.

May [9] studied the corrosion behavior of mild steel in varying concentrations of $\mathrm{NaCl}$ solutions. Weight loss technique was adopted for the experiment, and the result showed a low corrosion rate at higher concentration of $\mathrm{NaCl}$ and vice versa. The same approach was used by Ikechukwu et al. [10] in their experimental work on corrosion effect of carbon steel (API 5L X42) in different concentrations of $\mathrm{NaCl}, \mathrm{Na}_{2} \mathrm{SO}_{4}$, and $\mathrm{Na}_{2} \mathrm{CO}_{3}$ for a total exposure time of 1008 hours. They aim to determine the most aggressive environment for oil pipeline applications.

Poku et al. [11] performed experimental research on effect of temperature and salinity on corrosion rate of aluminum and mild steel. Machined mild steel and aluminum of different shapes were inserted into sodium chloride solution for seven days. Coupon technique was employed, and the corrosion rate was calculated accordingly. Corrosion rate of $0.1862 \mathrm{mmph}-0.2065 \mathrm{mmph}$ was obtained for aluminum at $35^{\circ} \mathrm{C}$ while $1.0567 \mathrm{mmph}-1.994 \mathrm{mmph}$ was obtained when the temperature rises to $65^{\circ} \mathrm{C}$. The same trend is observed for mild steel.

Liptáková et al. [12] carried out experiment on AISI 316L stainless steel. They investigated the effect of surface treatment on corrosion behavior of the selected metal welded by TIG method. Specimens were cut and prepared from the original plate AISI 316L $(120 \mathrm{~mm} \times 60 \mathrm{~mm})$ by waterjet cutting and welded by TIG method with using the filler. Specimen surface was finished by chemical (pickling) and mechanical methods (grinding, garnet blasting). Scanning electron microscopy (SEM) was used to analyze the morphological structure of the prepared surfaces. Corrosion resistance of the welded stainless steel was determined by the exposition test used for local corrosion evaluation and metallographic analysis. The result confirmed the significant effect of surface finishing on corrosion behavior of welded stainless steel AISI 316L.

Corrosion effect of mild steel (with or without surface protection) in cassava fluid under different working conditions was investigated by Durowoju and Oladosu [13]. Galvanized steel, painted mild steel, and normal steel were immersed in sweet cassava juice media for separate exposure time (continuous and intermittent). It was observed that galvanized steel has the highest corrosion rate compared to painted mild steel during the time of exposure, while normal steel with no surface protection has the least rate of corrosion during immersion duration.

Ayo et al. [14] employed weight loss techniques and SEM analysis to investigate steel corrosion cracking and microstructure analysis of mild steel in orange juice. The specimens were heat treated to different austenitic temperatures, cooled in water, and dipped in orange juice with a measured $\mathrm{pH}$ of 3.27 for 30 days. The weight loss of the sample was measured at 2-day intervals, and corrosion rate was calculated. The result revealed that SCC in mild steel is a function of acidity of the corrosive fluid and corrosion rate increases with increasing immersion time. In addition to this, resistance to corrosion attack increases at high austenitic temperature due to higher hardness obtained at higher temperature. 
TABLE 1: Detailed composition analysis of mild steel sample used in the experiment.

\begin{tabular}{lcccccccccccc}
\hline Elements & $\mathrm{C}$ & $\mathrm{Mn}$ & $\mathrm{P}$ & $\mathrm{S}$ & $\mathrm{Cr}$ & $\mathrm{Ni}$ & $\mathrm{Mo}$ & $\mathrm{V}$ & $\mathrm{Fe}$ & $\mathrm{Co}$ & $\mathrm{Cu}$ \\
\hline Wt.\% compositions & 0.165 & 1.29 & 0.0015 & 0.0062 & 0.0275 & 0.0183 & 0.0092 & 0.0076 & 98.1 & 0.0063 & 0.0548 \\
\hline
\end{tabular}

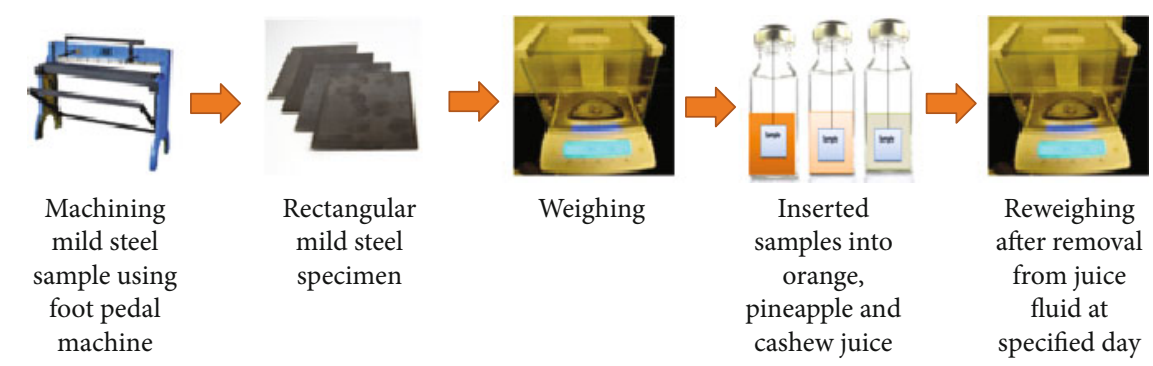

FIGURE 1: Specimen preparation process showing all the steps involved from the beginning to the end.

SEM analysis showed that the transgranular and intergranular attacks were responsible for corrosion of mild steel in orange juice environment.

In a related research, Afolabi et al. [15] used weight loss techniques during comparative analysis of corrosion behavior of mild steel in apple, orange, mango, and mixture of the juice for 60-day exposure time at 5-day interval material loss measurement. The highest corrosion rate was found in grape fruit losing about $4.69 \mathrm{~g}, 4.18 \mathrm{~g}$ loss in orange juice, $4.15 \mathrm{~g}$ loss in mixture fruit juice, and $4.10 \mathrm{~g}$ loss in apple, and mango has the lowest corrosion rate with weight about $2.25 \mathrm{~g}$ loss.

Ajide and Agara [16] performed experimental research on corrosion behavior of medium carbon steel (MCS) and KS7 stainless steel in natural orange fluid, cassava fluid, and distilled water using weight loss technique. Each specimen was exposed to $200 \mathrm{ml}$ of fluid for the 36-day immersion period with measurement taken at the 3-day interval to obtain the rate of corrosion. The result showed that KS7 SS has a high corrosion resistance compared to the MCS in the considered environment.

Based on the number of research publications centered on corrosion study in food processing industries, it can be inferred that little attention is paid to it. However, corrosion is a huge problem in this industry. Apart from failure of equipment and production downtime, there exists additional risk of product contamination as a result of corrosion product which may result in food poisoning and raise serious health concern. The above work indicates that no study has been conducted to examine the corrosion effect of mild steel in orange, cashew, and pineapple juice concurrently. At the same time, no single author analyzes this experimental result using design of experiment. The objective of the present investigation includes experimental study of mild steel sample of different thickness in orange, cashew, and pineapple juice and generation of the model equation for the 3-fruit juice environment using factorial experimental design. This statistical analysis would help to determine the contributory effect of varied parameters and the interactions between them. This study is of interest since systematic investigation of each parameter helps to decide the material to be used for food processing equipment in order to avoid food poisoning.

\section{Description of the Experiment}

The experiment was set up in the laboratory where mild steel specimen of thickness $1.0 \mathrm{~mm}$ and $1.5 \mathrm{~mm}$ was used. The samples were machined into rectangular sections, and they were treated by abrading them through successive grades of abrasive paper. Each sample was rinsed in distilled water and in acetone before drying. This procedure has been followed by Durowoju and Oladosu [13]. The prepared specimens were stored in desiccators to avoid atmospheric corrosion.

The fruits were obtained from the local market, and the experiment was carried out on a weekly basis. The weighed samples of the metal were suspended with the aid of a thread in the beakers each containing orange juice, pineapple juice, and cashew juice; and the beakers were kept stationary to avoid displacement effect. The exposure periods were a total of 25 days with measurements taken at an interval of 5 days, respectively. The specimens for orange, pineapple, and cashew media were taken out from the media, and the corrosive films were removed using a soft brush after which the samples were cleaned in distilled water properly before drying. The dried samples were weighed carefully in a weighing balance until a stable weight was achieved. Table 1 shows the chemical composition of mild steel sample used in this study; the analysis was conducted at Grand Foundry Limited, Ikeja, Lagos, using MiniPal 4 Spectrometer. Figure 1 gives a summary of the entire process of specimen preparation.

The average corrosion rates of mild steel in the environment under study were calculated using the method by [18-20].

$$
\mathrm{CR}=\frac{534 W}{\rho A T}
$$

where CR is the corrosion rate of the specimen in millimeter per year (mmpy), $W$ is the weight loss in $\mathrm{mg}, \rho$ is the density of metal in $\mathrm{mg} / \mathrm{m}^{3}, A$ is the area of specimen in $\mathrm{m}^{2}$, and $T$ is the exposure time in hours. 
TABLE 2: Design information.

\begin{tabular}{lcc}
\hline Factor & Factor levels & Values \\
\hline$A:$ media & 3 & Orange, pineapple, cashew \\
$B:$ duration (days) & 5 & $5,10,15,20,25$ \\
$C:$ thickness (mm) & 2 & $1.0,1.5$ \\
\hline
\end{tabular}

2.1. The General Factorial Design. This is a statistically based method that examines significant parameters in an experiment. It is useful in design of experiment where several factors and their interaction are to be considered. This design offers several advantages which include the smallest number of runs with which $k$ number of factors and all levels of factor combinations can be studied in a complete factorial experimental design. The results obtained from general factorial design are easily expressed in terms of the regression model. The coded regression model for general factorial design is shown [20] below.

$$
y=\beta_{0}+\sum_{i=1}^{k} \beta_{i} x_{i}+\sum_{1 \leq i \leq j}^{k} \beta_{i j} x_{i} x_{j}+\epsilon .
$$

This is a multiple regression model where $\beta_{0}$ is the average response in the experimental design and $\beta_{i}$ is the regression coefficients. The coefficient $\beta_{i j}$ denotes the interaction between $x_{i}$ and $x_{j}$. The error term $\epsilon$ is approximately normal and independently distributed with a mean of zero and constant variance. General factorial design was adopted in this work because of uneven factor levels, and single replicate was used to reduce cost of material for the experiment without affecting the eventual outcome.

Based on the available literatures and previous corrosion experiment, duration (days), thickness ( $\mathrm{mm}$ ), and media (orange, pineapple, and cashew) were found to be important parameters affecting the corrosion rate of mild steel and hence are used as the independent variables. The response (corrosion rate) was obtained by applying general factorial design with different factor levels; the design information about each parameter and corresponding levels are shown in Table 2.

There are three factors $(A, B$, and $C)$ at three, five, and two levels, respectively, with single replicate making a total of 30 experimental runs. Each trial of the experiment was randomized to avoid bias and to obtain accurate estimate of the error.

\section{Results and Discussion}

The corrosion rate was calculated using equation (1), and the obtained result was entered into a Minitab 17 commercial software for detailed analysis of experimental result. Table 3 shows the experimental matrix for the single-replicate general factorial design. The last column shows the response (corrosion rate) of each experimental run.

Since there are many factors at different levels under consideration, a single replicate or unreplicated factorial was found desirable for this analysis. With one replicate, there is
TABLE 3: General factorial design with three process parameters and responses on mild steel.

\begin{tabular}{|c|c|c|c|c|}
\hline $\begin{array}{l}\text { Experiment } \\
\text { number }\end{array}$ & Media & $\begin{array}{l}\text { Duration } \\
\text { (days) }\end{array}$ & $\begin{array}{l}\text { Thickness } \\
(\mathrm{mm})\end{array}$ & $\begin{array}{l}\text { Corrosion rate } \\
\text { (mmpy) }\end{array}$ \\
\hline 1 & 3 & 1 & 1 & 0.28 \\
\hline 2 & 3 & 4 & 1 & 0.12 \\
\hline 3 & 3 & 3 & 1 & 0.14 \\
\hline 4 & 3 & 3 & 2 & 0.29 \\
\hline 5 & 3 & 1 & 2 & 0.71 \\
\hline 6 & 3 & 2 & 2 & 0.41 \\
\hline 7 & 3 & 5 & 2 & 0.23 \\
\hline 8 & 3 & 2 & 1 & 0.19 \\
\hline 9 & 3 & 5 & 1 & 0.11 \\
\hline 10 & 3 & 4 & 2 & 0.25 \\
\hline 11 & 1 & 4 & 2 & 0.28 \\
\hline 12 & 1 & 2 & 1 & 0.16 \\
\hline 13 & 1 & 4 & 1 & 0.09 \\
\hline 14 & 1 & 2 & 2 & 0.41 \\
\hline 15 & 1 & 3 & 2 & 0.34 \\
\hline 16 & 1 & 1 & 1 & 0.19 \\
\hline 17 & 1 & 1 & 2 & 0.51 \\
\hline 18 & 1 & 3 & 1 & 0.12 \\
\hline 19 & 1 & 5 & 1 & 0.08 \\
\hline 20 & 1 & 5 & 2 & 0.24 \\
\hline 21 & 2 & 2 & 2 & 0.39 \\
\hline 22 & 2 & 4 & 2 & 0.25 \\
\hline 23 & 2 & 5 & 2 & 0.21 \\
\hline 24 & 2 & 4 & 1 & 0.21 \\
\hline 25 & 2 & 2 & 1 & 0.35 \\
\hline 26 & 2 & 1 & 1 & 0.48 \\
\hline 27 & 2 & 1 & 2 & 0.54 \\
\hline 28 & 2 & 5 & 1 & 0.08 \\
\hline 29 & 2 & 3 & 2 & 0.31 \\
\hline 30 & 2 & 3 & 1 & 0.27 \\
\hline
\end{tabular}

no internal estimate of error (or pure error). We sacrifice the higher-order interaction terms $(A, B$, and $C)$ after checking the percentage contribution of the main factors and interactions. Their mean squares are combined to estimate the error. The resulting ANOVA table for the factors and their corresponding $F$ and $P$ statistics are shown in Table 4 below.

The analysis of variance result allows for a statistical analysis of the contributions of the variables on the corrosion rate of mild steel (Table 4). Since the $P$ value for the model was less than 0.06 , there was a statistical relation between the response (corrosion rate) and the selected variables at $94 \%$ confidence level. The three main effects are significant $(P<0.06)$, and a significant two-way interaction was observed $(A \times C)$. The corrosion media $\times$ thickness of mild steel interactions shows that both factors significantly affect the corrosion rate of mild steel.

The adequacy of the model was good as there is a correlation between the dependent variable (corrosion rate) and 
TABLE 4: Analysis of variance (ANOVA) of general factorial design.

(a)

\begin{tabular}{cccccc}
\hline Source & DF & Adj. SS & Adj. MS & $F$ value & $P$ value \\
\hline Model & 21 & 0.64027 & 0.030489 & 11.15 & $\mathbf{0 . 0 0 1}$ \\
Linear & 7 & 0.55017 & 0.078595 & 28.74 & 0.000 \\
$A$ & 2 & 0.02249 & 0.011243 & 4.11 & $\mathbf{0 . 0 5 9}$ \\
$B$ & 4 & 0.31935 & 0.079837 & 29.19 & $\mathbf{0 . 0 0 0}$ \\
$C$ & 1 & 0.20833 & 0.208333 & 76.17 & $\mathbf{0 . 0 0 0}$ \\
2-way interactions & 14 & 0.09010 & 0.006436 & 2.35 & 0.113 \\
$A * B$ & 8 & 0.02661 & 0.003327 & 1.22 & 0.394 \\
$A * C$ & 2 & 0.04149 & 0.020743 & 7.58 & $\mathbf{0 . 0 1 4}$ \\
$B * C$ & 4 & 0.02200 & 0.005500 & 2.01 & 0.186 \\
Error & 8 & 0.02188 & 0.002735 & & \\
Total & 29 & 0.66215 & & & \\
\hline
\end{tabular}

(b) Model summary

\begin{tabular}{lccc}
\hline$S$ & R-sq & R-sq (adj) & R-sq (pred) \\
\hline 0.0522972 & $96.7 \%$ & $88.02 \%$ & $53.53 \%$ \\
\hline
\end{tabular}

the independent variables. This is seen in the R-sq value and Adj-R-sq value which are $96.70 \%$ and $88.02 \%$, respectively.

3.1. Capability Analysis. As the experiment is executed under the uniform experimental conditions (in terms of instrument/operator), we have carried out repeatability and capability analysis. For the said purpose, we have constructed a run chart (considered type I gage study) and performed the analysis to evaluate precision and bias. To carry out this analysis, we have adopted the following procedural flow.

For the corrosion rates of our experiment, we have computed various descriptive measures including mean, standard deviation, standard error, coefficient of variation (the variation relative to mean), and minimum/maximum values. All these descriptive measures are reported in Table 5 for our corrosion rate data set.

Using the above reported numbers, we have constructed the run chart for corrosion data. The resulting outcomes are given in the form of a run chart (see Figure 2 below). It is to be mentioned that we have done this under type I gage study that helps to evaluate the capability of a measurement process by combining the effects of bias and repeatability. It determines the amount of observed process variation due to the variation of the measurement system.

For the construction of the run chart and the other corresponding measures, we have used the following design settings:

(i) Reference: 0.3 (to be around the center)

(ii) Tolerance: upper specification - lower specification $=1.00$ (to capture the measurement variation within the tolerance bounds) (iii) Study variation: 6.0 (to estimate the variation in the measurements; the default choice is 6 , in order to capture the number of standard deviations needed to capture $99.73 \%$ of our measurements)

(iv) Percentage of tolerance: $99.73 \%$ (for the computation of capability indices $\mathrm{Cg}$ and $\mathrm{Cgk}$ )

The analysis reveals the following:

(i) Descriptive measures: these summary measures quantify various aspects of the data. Particularly, the mean (0.2747) gives the central location, standard deviation (0.1511) captures the average dispersion of data around the center, standard error (0.0276) quantifies the accuracy of the estimator to estimate the parameter, coefficient of variation (55.01) tells us the variation relative to mean (in percentage form), and minimum (0.08) and maximum (0.7100) provide the range of the data. All of these descriptive measures are very useful in explaining various numerical characteristics of the data, and experiments may benefit from them in their studies

(ii) Bias: the bias of the measurement system is reported as -0.025 . It results into a $t$ value equal to 0.9183 , and the corresponding $P$ value equals 0.366 (computed for a two-sided case using $\mathrm{DF}=29$ ). As $P$ value is quite large, we do not have evidence to reject the hypothesis of insignificant bias. It means that there is no bias present in the measurement system

(iii) Capability indices: we have considered two capability indices namely $\mathrm{Cg}$ and Cgk in our analysis. The index Cg compares the tolerance with the measurement variation, while Cgk compares the tolerance with both measurement variation and bias. The two indices are computed for the given data using the abovesaid design settings. The resulting indices are given as $\mathrm{Cg}=1.10$ and $\mathrm{Cgk}=1.04$ (both are below the traditional threshold of 1.33). Moreover, we obtained $\% \operatorname{Var}($ repeatability $)=90.66 \%$ and $\%$ $\operatorname{Var}($ repeatability and bias $)=95.52 \%$. In addition, we have also created a process capability report that provides information about the process data, its performance statistics, and the capability indices (both overall and potential). The resulting report in the form of a figure is provided in Figure 3

We notice from the run chart and process capability report that although we are well within specification, an improvement is still needed in the measurement system (as advocated by different indices reported therein).

The main effect plot is very important to us in this study since we have a categorical variable (media). This helps to compare the changes in mean levels in order to see the influence of the categorical variable on the response (corrosion rate). Figure 4 shows the main effect of each parameter studied, and it should be noted that the mean value is higher at one level of the variable than at another level. It is worth noting that the values taken by each point correspond to the 
TABle 5: Descriptive statistics: corrosion rates.

\begin{tabular}{llcccccc}
\hline Variable & $N$ & Mean & SE mean & StDev & CoefVar & Minimum & Maximum \\
\hline Corrosion rates & 30 & 0.2747 & 0.0276 & 0.1511 & 55.01 & 0.0800 & 0.7100 \\
\hline
\end{tabular}

Run chart of corrosion rates

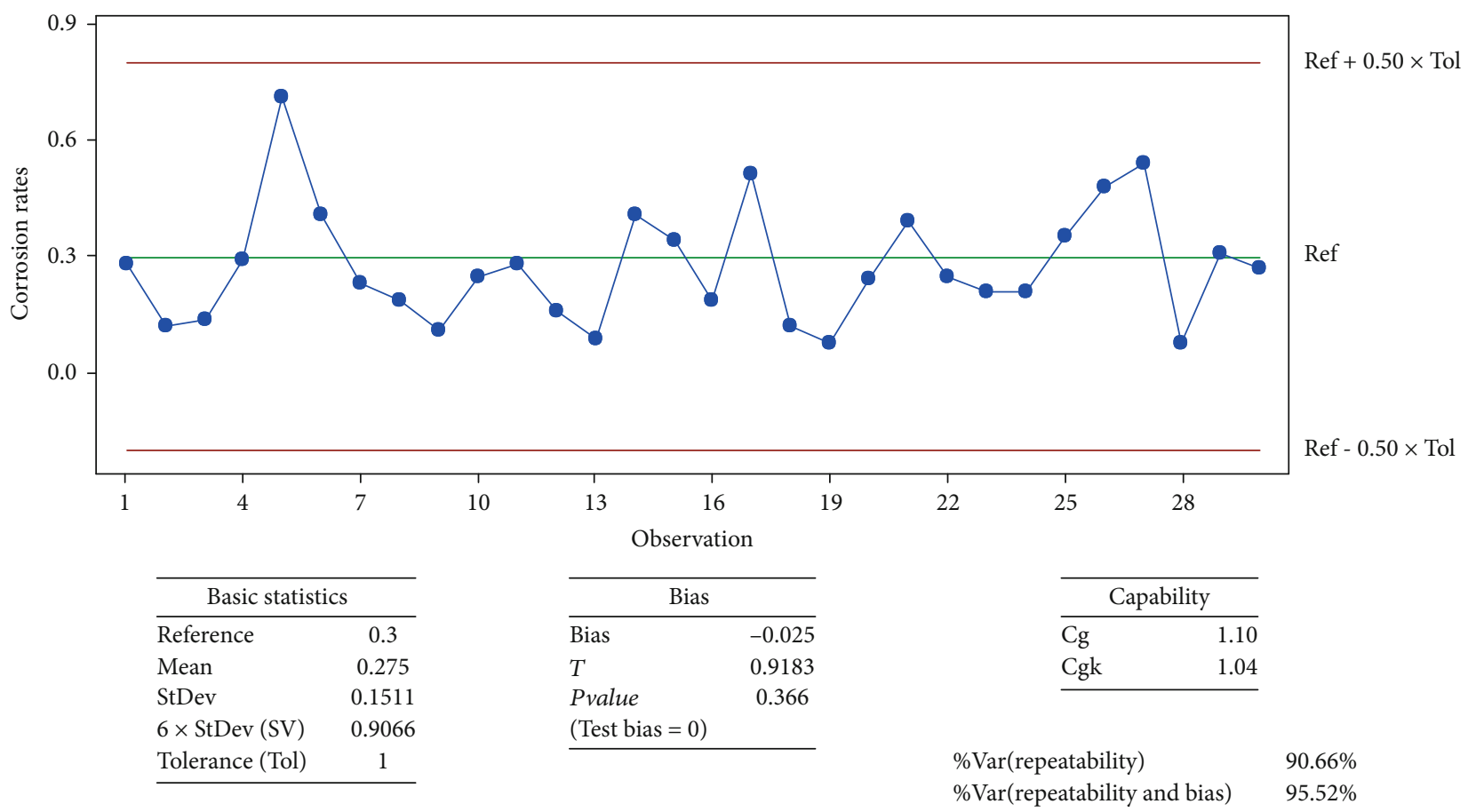

FIgURE 2: Run chart for the experimental data.

average of the corrosion rates obtained at this level, independently of the levels taken for other parameters, and the overall mean is plotted across each panel. The highest corrosion rates are obtained when mild steel is in cashew juice for 5day immersion time with a $1.5 \mathrm{~mm}$ thickness, and the lowest corrosion rates are obtained in orange juice for 25-day immersion time and $1.0 \mathrm{~mm}$ thickness.

Unlike the main effect plot which shows the influence of each process parameter on the material under study, the interaction plot provides the effect of two or more process variables on the response (corrosion rate). Figure 5 shows the interaction effect of the means of corrosion rates at different combinations of factor levels. Interaction $A * C$ was found to be significant since the lines are not parallel, and the slope of these variables is not horizontal. The changes in the response (corrosion rate) mean of mild steel in different media from the low to high levels of process variable depend on the level of the second process variable. Analysis of variance (ANOVA) for general factorial design presented in Table 4 also confirms the significance of interaction $A * C$. This shows that combination of mild steel sample thickness and media (fruit juice) has a significant effect on the corrosion rate of mild steel. The result from this statistical analysis is in good agreement with what was reported in Ref. [4].
3.2. Model Adequacy. Residual analysis was performed to check for validation of the underlying assumptions in ANOVA. These assumptions are that the observations are adequately described by equation (1) and that the error terms are normally and independently distributed with a mean of zero and an unknown but constant variance. These assumptions are abbreviated as $\operatorname{NID}\left(0, \sigma^{2}\right)$. The normality assumption was checked by plotting the histogram of the residuals as shown in Figure 6. There is nothing unusual with this plot as the residual is seen to be fairly distributed along the mean line and there is no possible outlier that reveals any nonnormality in the distribution. Furthermore, the plot of residual in time sequence is satisfactory as there is no positive correlation indicating violation of independence assumption, and lastly, the residual versus fitted value plot shows a structureless pattern illustrating that the assumption of constant variance is met.

3.3. Mathematical Model. Regression analysis was carried out to predict the value of a dependent variable (corrosion rate) based on the values of any of the independent variable and to establish a linear relationship between them, with factor $A$ specified as a categorical predictor and factors $B$ and $C$ as continuous predictors. The factor specification differs because factor $A$ is not a numerical factor unlike the other 
Process capability report for corrosion rates

\begin{tabular}{lc}
\hline \multicolumn{2}{c}{ Process data } \\
\hline LSL & -0.2 \\
Target & 0.3 \\
USL & 0.8 \\
Sample mean & 0.3 \\
Sample N & 30 \\
StDev(overall) & 0.152413 \\
StDev(within) & 0.139093 \\
\hline
\end{tabular}

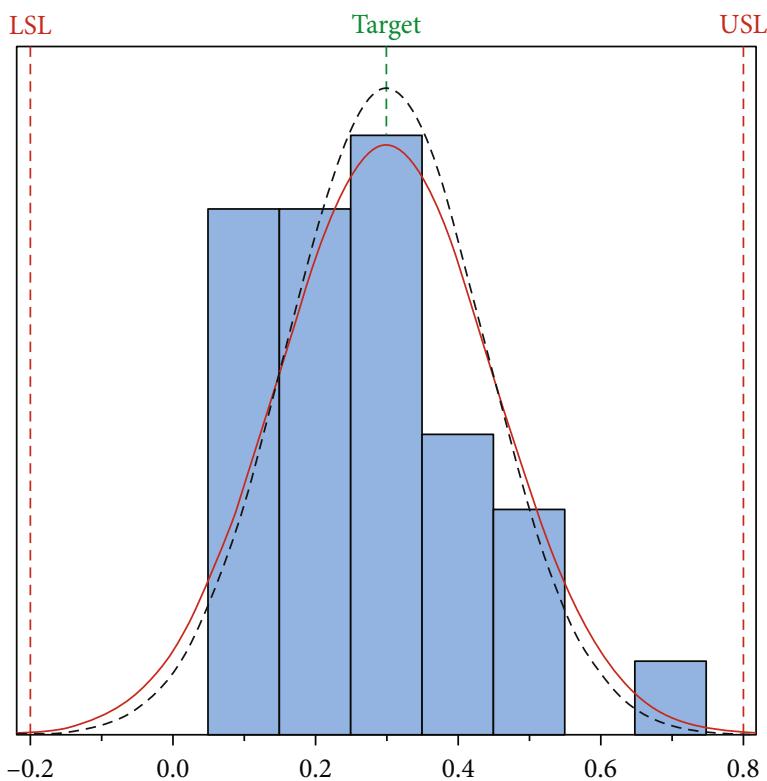

\begin{tabular}{lr}
\hline Overall capability \\
\hline Pp & 1.09 \\
PPL & 1.09 \\
PPU & 1.09 \\
Ppk & 1.09 \\
Cpm & 1.09 \\
\hline
\end{tabular}

$\overline{\text { Potential (within) capability }}$

\begin{tabular}{ll}
\hline $\mathrm{Cp}$ & 1.20 \\
$\mathrm{CPL}$ & 1.20 \\
$\mathrm{CPU}$ & 1.20 \\
$\mathrm{Cpk}$ & 1.20 \\
\hline
\end{tabular}

- Overall

-.. Within

\begin{tabular}{|c|c|c|c|}
\hline & Observed & $\begin{array}{l}\text { Performance } \\
\text { Expected overall }\end{array}$ & Expected within \\
\hline $\mathrm{PPM}<\mathrm{LSL}$ & 0.00 & 518.00 & 162.37 \\
\hline $\mathrm{PPM}<\mathrm{USL}$ & 0.00 & 518.00 & 162.37 \\
\hline PPM total & 0.00 & 1035.99 & 324.73 \\
\hline
\end{tabular}

Figure 3: Process capability report for the experimental data.

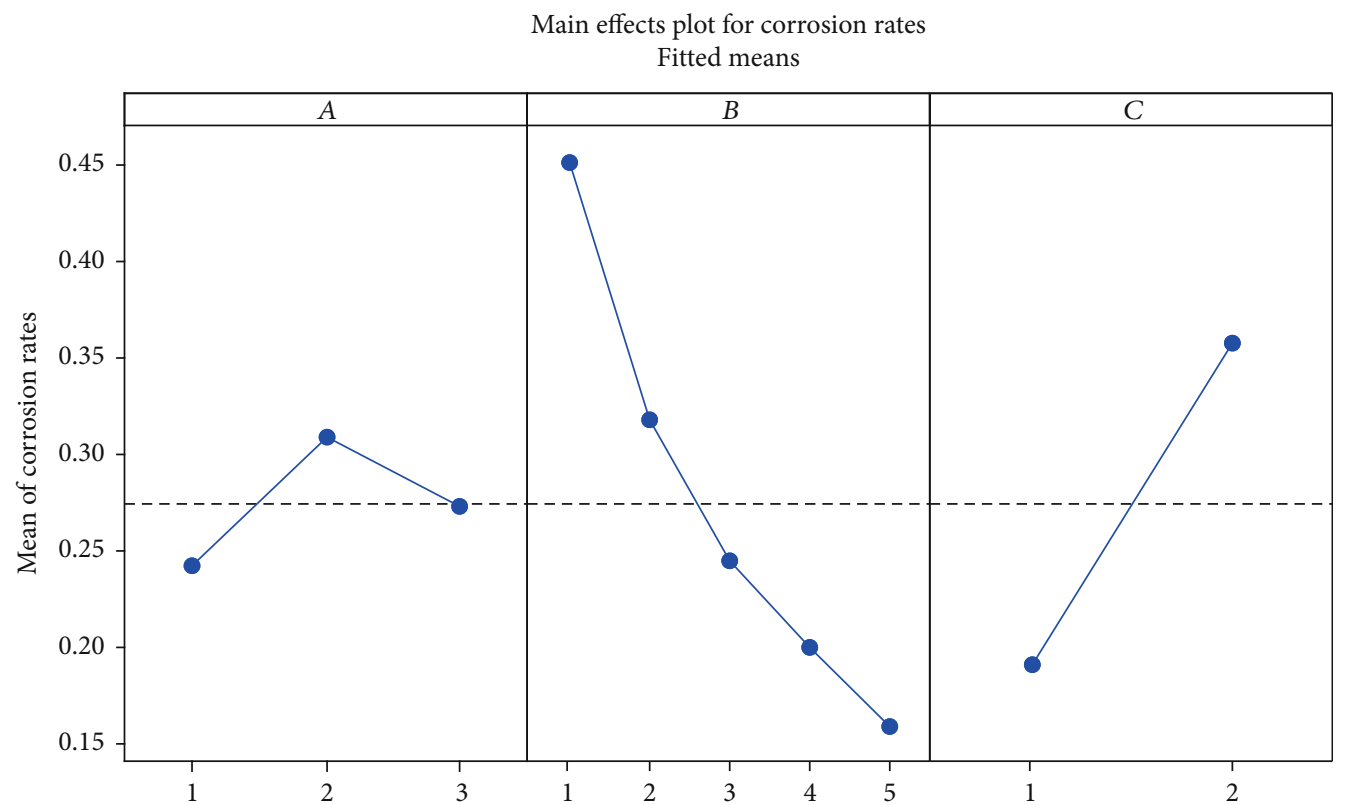

FIGURE 4: Main effect plots: corrosion rate means are represented as a function of the three factors (media, duration, and thickness). The dotted line illustrates the mean for all experiments. 


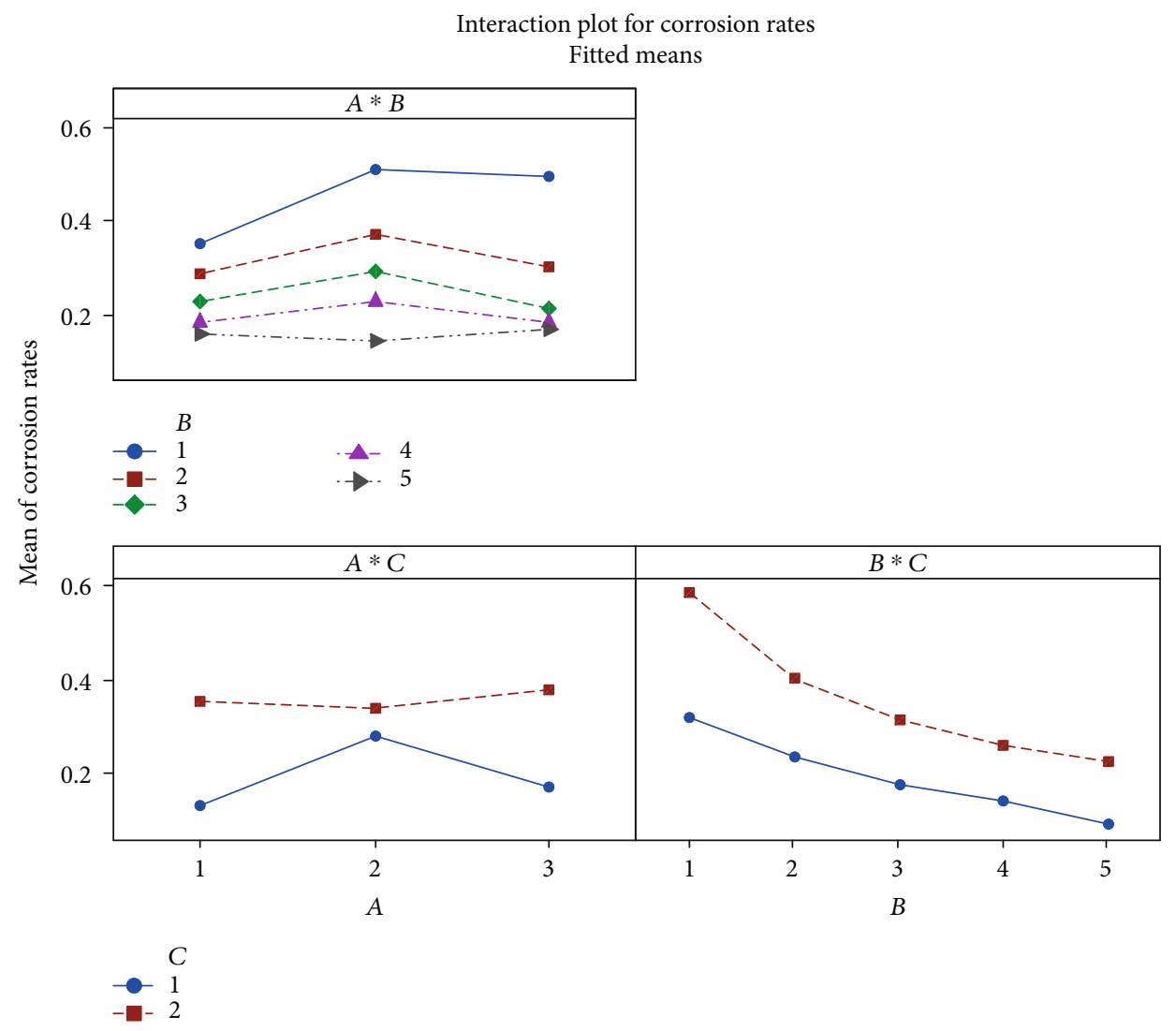

FIGURE 5: Interaction plot for corrosion rate of mild steel showing relationships between factors.

Residual plots for corrosion rates
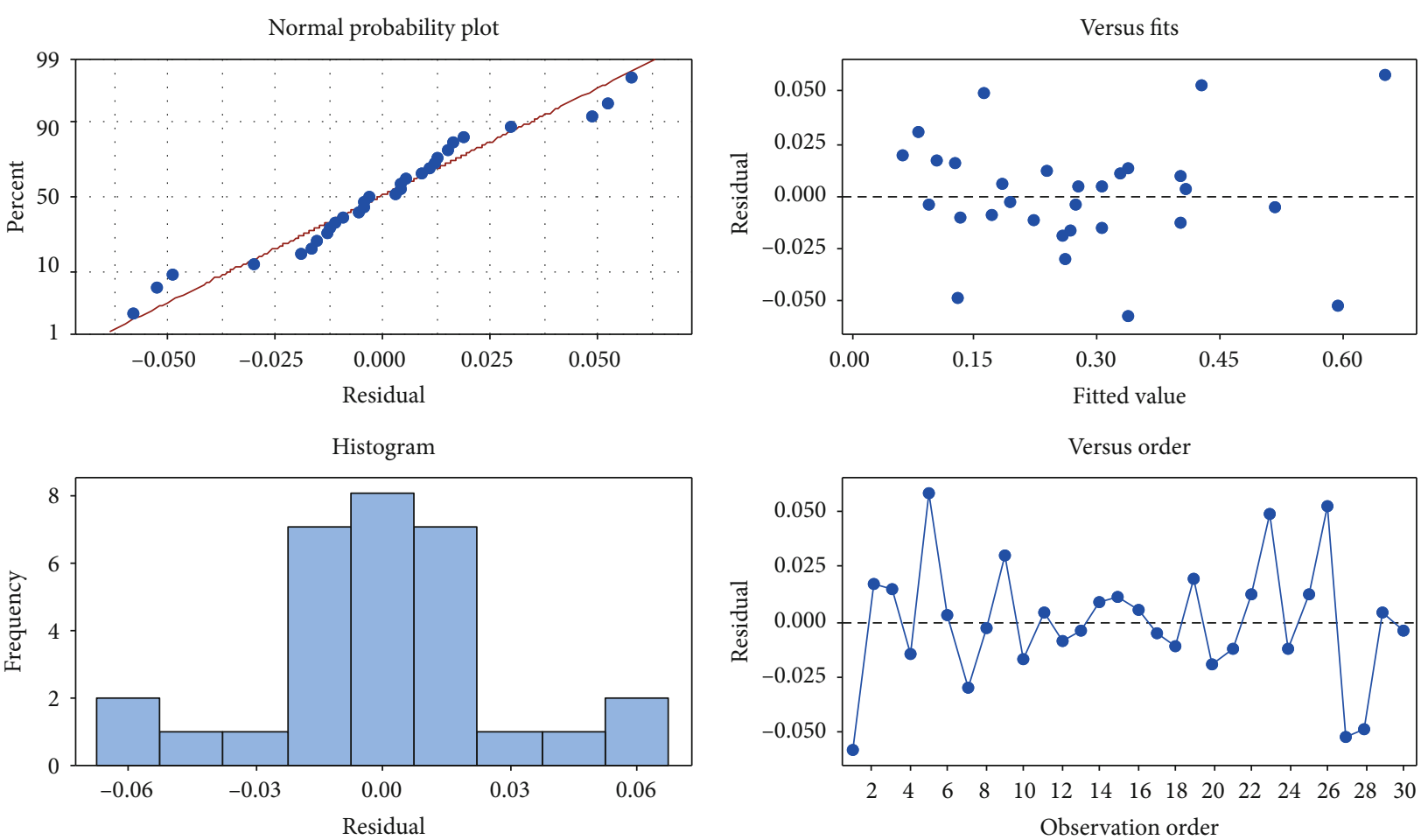

Figure 6: Residual plots for corrosion rates of mild steel showing the accuracy of the model used. 
two factors. The model equations for the corrosion rate of mild steel in the 3 different media are shown below.

$$
\begin{aligned}
& \text { Orange juice Corrosion rates } \\
& \quad=-0.0985-0.0005 B+0.3230 C-0.0317 B C, \\
& \text { Cashew juice Corrosion rates } \\
& \quad=0.3345-0.0395 B+0.1570 C-0.0317 B C,
\end{aligned}
$$

$$
\begin{aligned}
& \text { Pineapple juice Corrosion rates } \\
& \quad=-0.0985-0.0005 B+0.3230 C-0.0317 B C .
\end{aligned}
$$

The above model equations clearly show that corrosion is high in orange juices, moderately higher in pineapple juice, and highest in cashew juice. This agrees with the main effect and interaction plot analysis.

\section{Conclusion}

In this study, we have successfully analyzed the corrosion experimental result with Minitab 17 using general factorial design. The findings were in tandem with other corrosion experimental data analyses in the literature. Three design parameters media, duration, and thickness were selected as the variable. The result of the analysis of variance indicates that all the three main effects are important and interaction between media and thickness is important as well. This indicates that aggressiveness of the environment and service life is very important in design of food production and processing equipment. The result shows that the highest corrosion rate of $0.71 \mathrm{mmpy}$ occurs in cashew fluid with a $1.5 \mathrm{~mm}$ mild steel thickness. Moderate corrosion rate of $0.54 \mathrm{mmpy}$ is observed in pineapple fluid with $1.5 \mathrm{~mm}$ thickness, while the lowest corrosion rate of $0.08 \mathrm{mmpy}$ is noticed in both orange and pineapple fluid. Also, the corrosion rates are pronounced in the first week of the experiment while it declines towards the end of the experimental process. However, the variation between the thicknesses of the material does not have much influence on the corrosion rate, unlike the media and the duration.

Regression analysis was carried to obtain the linear relationships amongst variables. The model equation obtained from this analysis can be used to calculate the corrosion rate of mild steel for a similar condition with a very high accuracy. More research study should be done in the future to increase knowledge on corrosion situation in food processing industries to save the present and future generation to come from unwanted illness arising from contamination of food product.

\section{Data Availability}

Result data are available upon request.

\section{Conflicts of Interest}

The authors declare that they have no conflicts of interest.

\section{References}

[1] S. K. Amit, M. M. Uddin, R. Rahman, S. M. R. Islam, and M. S. Khan, "A review on mechanisms and commercial aspects of food preservation and processing," Agriculture \& Food Security, vol. 6, no. 1, pp. 1-22, 2017.

[2] J. W. Neckers and T. W. Abbott, "Acids occurring naturally in fruits," School Science and Mathematics, vol. 36, no. 9, pp. $986-$ 992, 1936

[3] G. H. Koch, M. P. H. Brongers, N. G. Thompson, Y. P. Virmani, and J. H. Payer, "Cost of corrosion in the United States," in Handbook of Environmental Degradation of Materials, pp. 3-24, William Andrew Publishing, 2005.

[4] A. Y. Badmos and H. A. Ajimotokan, The corrosion of mild steel in orange juice environment, Technical Report, No: 2009-02, 2009.

[5] M. R. Sharma, N. Mahato, M. H. Cho, T. P. Chaturvedi, and M. M. Singh, "Effect of fruit juices and chloride ions on the corrosion behavior of orthodontic archwire," Materials and Technologies, vol. 34, no. 1, pp. 18-24, 2019.

[6] S. Dey and M. K. Agrawal, "Investigation of corrosion behavior of TinplateIn fruit juice," International Journal of Engineering and Technology, vol. 9, pp. 234-242, 2017.

[7] A. Omotoso, P. O. Aiyedun, O. R. Adetunji, T. A. Arowolo, and F. T. Owoeye, "Corrosion performance of 1014 mild and 304 stainless steels in acidic media," Journal of Natural Sciences Engineering and Technology, vol. 16, no. 1, pp. 83-92, 2017.

[8] H. D. Ada, S. Altanlar, F. Erdem, and G. Bereket, "Investigation of corrosion resistance of steel used in beet sugar processing juices," International Journal of Industrial Chemistry, vol. 7, no. 4, pp. 431-439, 2016.

[9] M. May, "Corrosion behavior of mild steel immersed in different concentrations of $\mathrm{NaCl}$ solutions," Journal of Sebha University, vol. 15, pp. 1-12, 2016.

[10] A. S. Ikechukwu, E. Obioma, and N. H. Ugochukwu, "Studies on corrosion characteristics of carbon steel exposed to $\mathrm{Na}_{2} \mathrm{CO}_{3}, \mathrm{Na}_{2} \mathrm{SO}_{4}$ and Nacl solutions of different concentrations," International Journal of Engineering Science, vol. 3, no. 10, pp. 48-60, 2014.

[11] R. Poku, B. O. Lucky, and E. A. Ogbonnaya, "Effects, evaluation and corrosion of heat exchangers performance in seawater," American Journal of Engineering Research, vol. 4, no. 9, pp. 87-95, 2015.

[12] M. Halamova, T. Liptakova, A. Alaskari, and F Bolzoni, "Influence of surface structure on corrosion behaviour of welded stainless steel AISI 316L," Communications-Scientific Letters of the University of Zilina, vol. 16, no. 1, pp. 78-83, 2014.

[13] M. O. Durowoju, I. A. Babatunde, O. J. Adedoyin, and K. Oladosu, "Corrosion effect of sweet cassava fluid on steels under different working conditions," IOSR Journal of Mechanical and Civil Engineering, vol. 11, no. 4, pp. 50-55, 2014.

[14] A. S. Afolabi, T. G. Ngwenya, O. K. Sanusi, and A. S. Abdulkareem, "Stress corrosion cracking of a mild steel in orange juice," in Proceeding of the World Congress on Engineering, vol. 1, pp. 13-20, 2013.

[15] A. S. Afolabi, A. C. Ogazi, and A. S. Abdulkareem, "Comparative weight loss analyses of mild steel in agro fluid media," International Conference on Chemical, Mining and Metallurgical Engineering (CMME'2013), 2013, Johannesburg, South Africa, November 2013, 2013. 
[16] O. O. Ajide, K. W. Agara, and A. A. Adegbola, "Investigating corrosion performance of MCS and KS7 SS in different fluid environments," International Journal of Science and Technology, vol. 1, no. 5, 2012.

[17] J. E. Ovri and T. B. Ofeke, "The corrosion of mild steel in marine environment," Journal of Science Engineering Technology, vol. 5, no. 2, pp. 117-1129, 1998.

[18] G. O. Avwiri, "Corrosion resistance of copper and brass in various media," Journal of Corrosion Science and Technology, vol. 1, no. 1, pp. 58-90, 2004.

[19] E. Osarolube, I. O. Owate, and N. C. Oforka, "The influence of acidity concentrations on corrosion of copper and zinc," Journal of Corrosion Science and Technology, vol. 1, pp. 66-69, 2004.

[20] D. C. Montgomery, Design and analysis of experiments. Eighth, John Wiley \& Sons inc., Hoboken, NJ, USA, 2013. 